OPEN ACCESS

Edited by: Gabriella Martino, University of Messina, Italy

Reviewed by:

Annalisa Tanzilli,

Sapienza University of Rome, Italy

Marco Guicciardi,

University of Cagliari, Italy

*Correspondence:

Mariagrazia Di Giuseppe Mariagrazia.digiuseppe@gmail.com

Specialty section: This article was submitted to

Psychopathology, a section of the journal Frontiers in Psychology

Received: 17 May 2020

Accepted: 09 July 2020

Published: 11 September 2020

Citation:

Conversano C, Di Giuseppe M, Miccoli M, Ciacchini R, Gemignani A and Orrù G (2020) Mindfulness, Age and Gender as Protective Factors Against Psychological Distress During

COVID-19 Pandemic.

Front. Psychol. 11:1900.

doi: 10.3389/fpsyg.2020.01900

\section{Mindfulness, Age and Gender as Protective Factors Against Psychological Distress During COVID-19 Pandemic}

\author{
Ciro Conversano ${ }^{1}$, Mariagrazia Di Giuseppe ${ }^{1 *}$, Mario Miccoli ${ }^{2}$, Rebecca Ciacchini ${ }^{1}$, \\ Angelo Gemignani ${ }^{1}$ and Graziella Orrù ${ }^{1}$
}

1 Department of Surgical, Medical and Molecular Pathology, Critical and Care Medicine, University of Pisa, Pisa, Italy,

${ }^{2}$ Department of Clinical and Experimental Medicine, University of Pisa, Pisa, Italy

Objective: Mindfulness disposition is associated with various psychological factors and prevents emotional distress in chronic diseases. In the present study, we analyzed the key role of mindfulness dispositions in protecting the individual against psychological distress consequent to COVID-19 social distancing and quarantining.

Methods: An online survey was launched on March 13, 2020, with 6,412 responses by April 6, 2020. Socio-demographic information, exposure to the pandemic, and quarantining were assessed together with psychological distress and mindfulness disposition. Multivariate linear regression analysis was performed to study the influence of predictive factors on psychological distress and quality of life in Italian responders during the early days of lockdown. Pearson correlations were calculated to study the relationship between mindfulness and psychiatric symptoms.

Results: Multivariate linear regression run on socio-demographics, COVID-19-related variables, and mindfulness disposition as moderators of overall psychological distress showed that mindfulness was the best predictor of psychological distress ( $\beta=-0.504$; $p<0.0001)$. High negative correlations were found between mindfulness disposition and the overall Global Severity Index $(r=-0.637 ; p<0.0001)$, while moderate to high associations were found between mindfulness and all SCL-90 sub-scales.

Discussion: Findings showed that high dispositional mindfulness enhances wellbeing and helps in dealing with stressful situations such as the COVID-19 pandemic. Mindfulness-based mental training could represent an effective intervention to stem post-traumatic psychopathological beginnings and prevent the onset of chronic mental disorders.

Keywords: mindfulness, COVID-19, pandemic, meditation, psychological distress, SCL-90, MAAS, adjustment 


\section{INTRODUCTION}

The current global COVID-19 pandemic has negatively impacted mental health worldwide. In order to respond most effectively to this emergency, an immediate international response from mental health professionals is needed (Aafjes-van Doorn et al., 2020; Conversano et al., 2020b; Fisher et al., 2020; Holmes et al., 2020; Muratori and Ciacchini, 2020). Researchers across the world are promptly trying to address this issue by screening the psychological impact of social distancing and quarantining (Brooks et al., 2020; Orrù et al., 2020; Poli et al., 2020). Results from early studies using social media like Twitter and Weibo data have found that posts related to negative emotions and sensitivity to social risks have greatly increased during lockdown (Kwon et al., 2020; Li et al., 2020). Consistent with these findings, another study on the psychological impact of COVID-19 among Italians during the first week of lockdown has found that $40 \%$ of participants reported high psychological distress and about 30\% showed clinically significant post-traumatic symptoms (Marazziti et al., 2020). Conversely, adaptive defensive functioning has been found associated with better adjustment and fewer posttraumatic symptoms (Di Giuseppe et al., 2020a). In the present study, we have analyzed the impact of mindfulness dispositions as a protective factor against psychological distress.

In reference to the so-called protective factors in a lowered stress impact perspective, the literature identifies some human abilities already described in ancient times (i.e., Buddhism and other contemplative traditions), which may represent some valid tools in dealing with stress. These abilities may vary from different cognitive processes such as attention, memory, and thought. One of these cognitive processes may be represented by mindfulness, the experience of awareness which is activated by purposely paying attention to what occurs in the present, with a non-judgmental attitude (Kabat-Zinn, 2015). In other words, mindfulness may be defined as a process involving attention, awareness, and an open-minded acceptance of the present moment; it concerns the quality of consciousness itself and it is not identified with reflective thought but "offers a bare display of what is taking place" in the moment of observation (Shear and Jevning, 1999, p. 204).

Many researchers, in the last 30 years, have studied this human ability, identifying its intrinsic nature in the human being and its possible enhancement through environmental and behavioral training (Brown and Ryan, 2003; Kabat-Zinn, 2003). To date, this mindfulness ability seems to be related to other psychological constructs such as emotional intelligence, vivid perception, receptive attention, personality traits, and defense mechanisms (Salovey et al., 1995; Costa and McCrae, 2008; Marazziti et al., 2015; Di Giuseppe et al., 2019a). Mindfulness has also been proven to represent a good predictor of depression, anxiety, stress, and well-being in association with self-compassion, selfefficacy, and gender (Soysa and Wilcomb, 2015; Conversano et al., 2020a). Dispositional mindfulness has the potential to be used as treatment for stress-related and other mental health disorders (Baer, 2003; Chang et al., 2004) and is effective in the enhancement of immune function (Davidson et al., 2003) and self-regulation, through the training of attention control, emotion regulation, and self-awareness (Tang et al., 2015; Geng et al., 2019). Interestingly, similar findings were shown in recent studies concerning the key role of defense mechanisms and related psychological functions in chronic illness (Di Giuseppe et al., 2018, 2019b, 2020b; Catalano et al., 2019; Conversano, 2019; Merlo, 2019; Marchi et al., 2019; Lenzo et al., 2020; Martino et al., 2019a,b, 2020a). In particular, mood disorders seem to negatively affect physical and psychological response to treatment in chronic patients (Marazziti et al., 2008; Mula et al., 2008; Dell'Osso et al., 2012; Piccinni et al., 2012; Veltri et al., 2012; Martino et al., 2019c, 2020b). Recent studies demonstrated that mindfulness disposition is related to anxiety and depression and this is observable among different clinical populations (Idusohan-Moizer et al., 2015; Zhang et al., 2015; Lam et al., 2020). Several systematic reviews and meta-analyses showed significant beneficial effects on depressive and anxiety symptoms in patients treated with mindfulness-based interventions (Strauss et al., 2014; Chu et al., 2018).

As regards the measurement of mindfulness levels, there are different validated tools available for scientific research, each of which focuses on different operational definitions (Baer et al., 2004; Baer et al., 2006). The Mindful Attention Awareness Scale (MAAS; Brown and Ryan, 2003) is a psychological instrument to assess the presence or absence of attention to and awareness of what is occurring in the present moment for the participants. It focuses on the above-mentioned core characteristic of mindfulness, which has a dispositional quality. From the validation study of the MAAS, this unique quality of consciousness seems to be related to, and predictive of, a variety of self-regulation and well-being constructs such as optimism, satisfaction, vitality, and self-esteem, and negatively correlated with anxiety, depression, impulsiveness, and self -monitoring (Ryan and Deci, 2000; Brown and Ryan, 2003).

In the present study, regarding the Italian population during the COVID-19 pandemic, we sought to (1) identify individuals at higher risk for psychological distress while measuring the weight of mindfulness disposition in protecting their mental health and (2) assess the relationship between mindfulness and several psychiatric symptoms of distress. Regarding the first hypothesis, we expected that socio-demographic characteristics and lockdown duration would negatively affect psychological well-being, while higher mindfulness would lower the levels of distress. Regarding the second hypothesis, we expected that higher mindfulness disposition would be associated with lower self-rated psychiatric symptoms and lower overall psychological distress.

\section{MATERIALS AND METHODS}

\section{Participants}

From March 13 to April 6, 2020, we collected 6,412 responses from people living in Italy to an online survey about the psychological impact of COVID-19 during the lockdown. Responders were mostly middle-aged adults between 30 and 50 years old, while approximately 33 and $27 \%$ were younger and older, respectively. Most of the sample was represented by 
TABLE 1 | Descriptive statistics of responders' socio-demographic characteristics $(N=6,412)$.

\begin{tabular}{|c|c|c|}
\hline & $N$ & $\%$ \\
\hline \multicolumn{3}{|l|}{ Age } \\
\hline$<30$ & 2,099 & 32.7 \\
\hline $30-50$ & 2,572 & 40.1 \\
\hline$>50$ & 1,741 & 27.2 \\
\hline \multicolumn{3}{|l|}{ Gender } \\
\hline Male & 1,604 & 25.0 \\
\hline Female & 4,808 & 75.0 \\
\hline \multicolumn{3}{|l|}{ Location } \\
\hline North Italy & 1,603 & $25 \%$ \\
\hline Central Italy & 3,463 & $54 \%$ \\
\hline South Italy & 1,346 & $21 \%$ \\
\hline \multicolumn{3}{|l|}{ Living with } \\
\hline Close relatives & 4,508 & 70.3 \\
\hline Partners & 838 & 13.1 \\
\hline Roommate & 286 & 4.4 \\
\hline Alone & 780 & 12.2 \\
\hline \multicolumn{3}{|l|}{ Having children } \\
\hline Yes & 2,619 & 40.8 \\
\hline No & 3,793 & 59.2 \\
\hline \multicolumn{3}{|c|}{ Positive cases among relatives and friends } \\
\hline Yes & 417 & $7 \%$ \\
\hline No & 5,995 & $93 \%$ \\
\hline \multicolumn{3}{|l|}{ Deaths among relatives and friends } \\
\hline Yes & 167 & $3 \%$ \\
\hline No & 6,245 & $97 \%$ \\
\hline
\end{tabular}

females, living with close relatives, without children (see Table $\mathbf{1}$ for descriptive statistics). Participants prevalently came from Central Italy $(N=3,463 ; 54 \%)$, whereas $25 \%(N=1,603)$ and $21 \%(N=1,346)$ were in the North and the South of Italy, respectively. The rates of reported positive cases and deaths among close relatives or friends were about $7 \%(N=417)$ and $3 \%(N=167)$, respectively.

\section{Measures}

To evaluate psychological distress and individual adaptive responses we conducted a survey exploring sociodemographic information, COVID-19-related information (i.e., presence/absence of positive cases or death among relatives or friends), psychological distress, and mindfulness disposition. The Italian version of the Symptoms Checklist-90 (SCL-90; Derogatis et al., 1973; Cassano et al., 1999) and the Mindfulness Attention Awareness Scale (MAAS; Brown and Ryan, 2003; Veneziani and Voci, 2015) were used for the assessment of psychological variables.

The Symptoms Checklist-90 is a 90-item 5-point scale assessing psychopathological and somatic symptoms occurring during the past week. Even if it does not control for deceptive responses (Sartori et al., 2017), in this specific setting is adequate given the absence of faking proneness in respondents. The SCL-90 provides a Global Severity Index (GSI) and nine subscale scores for psychiatric symptoms, such as Somatization (SOM), Obsessive
Compulsive Disorder (O-C), Interpersonal Sensitivity (I-S), Depression (DEP), Anxiety (ANX), Hostility (HOS), Phobic Anxiety (PHOB), Paranoid Ideation (PAR), and Psychoticism (PSY). Validity and reliability of the scale have been largely documented (Derogatis et al., 1976; Derogatis and Cleary, 1977; Bonicatto et al., 1997; Lara et al., 2005).

The Mindfulness Attention Awareness Scale is a 15-item singledimension measure of the frequency of open and receptive attention to, and awareness of, ongoing events and experience using a 6-point Likert. All items are presented as negative descriptions of mindfulness, so higher scores indicate less mindfulness. For the purpose of the study, we adapted the MAAS, resulting in a reversed 5-point Likert scale, so higher scores indicated greater mindfulness. The MAAS is a reliable instrument with a Cronbach's $\alpha$ of 0.87 . Adequate test-retest reliability, and convergent as well as discriminate validity have been reported (Black et al., 2012).

\section{Procedure}

An online questionnaire was launched online on March 13, 2020, at 17:00 (GMT + 1), 2 days after the Italian Government Decree of lockdown for slowing the diffusion of the COVID-19 outbreak. Participants were recruited using snowball sampling among all Italian residents living in Italy at the time of data collection. They were informed about the purpose of the study and asked to give their approval on personal data treatment. All procedures followed the ethical standards and were approved by the Ethics Committee of the University of Pisa (n. 0036344/2020).

\section{Statistical Analyses}

Descriptive data are presented as means, standard deviations, 95\% confidence intervals, absolute and relative frequencies. The Anderson-Darling test and Normal P-P plot were used to verify normality of distributions. Pearson correlation coefficients were calculated, $t$-test and simple linear regressions were performed to study the relations between the variables and the outcome. Multivariate analysis was carried out to study the influence of predictive factors on psychological distress. Tolerance index and Variance Inflation Factor (VIF) were calculated to verify the level of correlation between predictors. Tolerance values were $>0.5$ and VIF values were $<2$, these results showed no evidence of multicollinearity. Goodness of fit of the multivariate analysis was verified, adjusted $R^{2}$ resulted 0.43 , showing a good level of fit model. Post hoc power analysis was used to evaluate the sample size and the probability of type II error; the range of statistical power was $0-1$ and the power of the sample was 1 . The significance level was set to 0.05 and the analyses were performed with $\mathrm{R}$ version 4.0.0.

\section{RESULTS}

Table 1 shows descriptive statistics for socio-demographic characteristics of participants. In line with previous studies, young, female, living with parents, and not having children were more frequent among responders. Descriptive statistics for psychological variables are displayed in Table 2 . 
TABLE 2 | Descriptive statistics of responders' psychological characteristics $(N=6,412)$.

\begin{tabular}{|c|c|c|c|c|}
\hline & \multirow[t]{2}{*}{ Mean } & \multirow[t]{2}{*}{$S D$} & \multicolumn{2}{|c|}{$95 \%$ interval confidence } \\
\hline & & & Lower & Upper \\
\hline Mindfulness (MAAS) & 2.881 & 0.653 & 2.865 & 2.897 \\
\hline Psychological distress (SCL-90 GSI) & 0.730 & 0.536 & 0.717 & 0.743 \\
\hline SCL-90 SOM & 0.622 & 0.605 & 0.607 & 0.637 \\
\hline SCL-90 O-C & 0.872 & 0.683 & 0.855 & 0.889 \\
\hline SCL-90 INT & 0.607 & 0.588 & 0.592 & 0.621 \\
\hline SCL-90 DEP & 0.977 & 0.746 & 0.958 & 0.995 \\
\hline SCL-90 ANX & 0.860 & 0.694 & 0.843 & 0.877 \\
\hline SCL-90 HOS & 0.650 & 0.613 & 0.635 & 0.665 \\
\hline SCL-90 PHOB & 0.478 & 0.548 & 0.465 & 0.492 \\
\hline SCL-90 PAR & 0.713 & 0.665 & 0.697 & 0.730 \\
\hline SCL-90 PSY & 0.509 & 0.522 & 0.497 & 0.522 \\
\hline SCL-90 SLEEP & 1.076 & 0.982 & 1.052 & 1.100 \\
\hline
\end{tabular}

TABLE 3 | Univariate linear regressions for socio-demographic variables and mindfulness predicting psychological distress.

\begin{tabular}{lrrrrrr}
\hline & \multicolumn{7}{c}{ Global Severity Index (GSI) } \\
\cline { 2 - 7 } & $\boldsymbol{\beta}$ & SE & $\boldsymbol{t}$ & $\boldsymbol{P}$ & $\mathbf{9 5 \%}$ CI \\
\hline Age & -0.072 & 0.004 & -16.120 & $<0.0001$ & -0.081 & -0.063 \\
Gender (female) & 0.175 & 0.015 & 11.436 & $<0.0001$ & 0.145 & 0.205 \\
Having children & -0.141 & 0.013 & -10.446 & $<0.0001$ & -0.167 & -0.114 \\
Location Central Italy & -0.017 & 0.018 & -0.996 & 0.319 & -0.052 & 0.017 \\
Location South Italy & -0.039 & 0.021 & -1.863 & 0.063 & -0.079 & 0.002 \\
Positive cases & 0.046 & 0.027 & 1.682 & 0.093 & -0.008 & 0.099 \\
Deaths & 0.040 & 0.042 & 0.939 & 0.348 & -0.043 & 0.122 \\
Living with lover & 0.133 & 0.033 & 4.079 & $<0.0001$ & 0.069 & 0.197 \\
Weeks in lockdown & 0.052 & 0.008 & 6.183 & $<0.0001$ & 0.036 & 0.069 \\
Mindfulness (MAAS) & -0.504 & 0.008 & -64.169 & $<0.0001$ & -0.519 & -0.488 \\
\hline Location Central Italy & and & Location & South Italy & resulted & non-significant in \\
comparison with Location North Italy. & & & &
\end{tabular}

Mindfulness mean scores assessed around normative values for healthy individuals $(M=2.881 ; S D=0.653)$, while psychological distress mean score ranged slightly below the cut-off for clinical significance $(M=0.730$; $S D=0.536)$. These results indicated that responders represented a community sample experiencing a stressful life event such as the lockdown as a consequence of the COVID-19 outbreak.

Tables 3, 4 show results from univariate and multivariate linear regression run on socio-demographic variables and mindfulness disposition as predictors of overall psychological distress are displayed. Table 3 shows results of preliminary univariate linear regression analyses of all socio-demographic variables on the GSI. We entered in the multivariate linear regression model only variables that resulted significantly related to the GSI. Variables included were age, gender, quarantine, people living with, having children, and mindfulness. Table 4 shows that all factors resulted significantly, with the only exception of having children that was no longer
TABLE 4 | Multivariate linear regression for socio-demographic variables and mindfulness predicting psychological distress.

\begin{tabular}{lrrrrrrr}
\hline & \multicolumn{7}{c}{ Global Severity Index (GSI) } \\
\cline { 2 - 7 } & $\boldsymbol{\beta}$ & SE & $\boldsymbol{t}$ & $\boldsymbol{P}$ & $\mathbf{9 5 \%}$ CI \\
\hline Age & -0.039 & 0.005 & -8.320 & $<0.0001$ & -0.048 & -0.030 \\
Gender (female) & 0.078 & 0.012 & 6.570 & $<0.0001$ & 0.054 & 0.101 \\
Living with lover & -0.040 & 0.016 & -2.527 & 0.012 & -0.072 & -0.009 \\
Weeks in lockdown & 0.050 & 0.006 & 7.846 & $<0.0001$ & 0.038 & 0.063 \\
Mindfulness (MAAS) & -0.504 & 0.008 & -64.169 & $<0.0001$ & -0.519 & -0.488 \\
Having children & -0.021 & 0.014 & -1.478 & 0.140 & -0.050 & 0.007 \\
\hline
\end{tabular}

Living with lover is significant in comparison to living with parents, whereas either living alone or with roommates resulted non-significant in comparison to living with parents.

TABLE 5 | Pearson correlations between mindfulness disposition (MAAS) and psychological distress (SCL-90).

\begin{tabular}{lcc}
\hline & \multicolumn{2}{c}{ MAAS $(\mathbf{N = 6 , 4 1 2})$} \\
\cline { 2 - 3 } & $\boldsymbol{r}$ & $\boldsymbol{p}$ \\
\hline GSI & -0.637 & $<0.0001$ \\
SCL-90 SOM & -0.466 & $<0.0001$ \\
SCL-90 O-C & -0.627 & $<0.0001$ \\
SCL-90 INT & -0.551 & $<0.0001$ \\
SCL-90 DEP & -0.565 & $<0.0001$ \\
SCL-90 ANX & -0.536 & $<0.0001$ \\
SCL-90 HOS & -0.487 & $<0.0001$ \\
SCL-90 PHOB & -0.415 & $<0.0001$ \\
SCL-90 PAR & -0.533 & $<0.0001$ \\
SCL-90 PSY & -0.593 & $<0.0001$ \\
SCL-90 SLEEP & -0.386 & $<0.0001$ \\
\hline
\end{tabular}

significant in the final model. Mindfulness resulted the best predictor of GSI, about 10 times more effective than other predictors included. Each increase of one unit of MAAS results in a decrease of -0.5 in GSI $(\beta=-0.504 ; p<0.0001)$. Conversely, quarantining negatively affected mental health, increasing GSI of 0.05 for each week passed in lockdown. Younger subjects and females were at higher risk for mental health problems, while living with one's spouse resulted in them feeling slightly protected in terms of psychological wellbeing. VIF $<2$ demonstrated low collinearity level between independent variables.

Table 5 shows Pearson correlations between MAAS and SCL-90. High negative correlations were found for mindfulness disposition and overall psychological distress $(r=-0.637$; $p<0.0001$ ), obsessive compulsive (O-C; $r=-0.627 ; p<0.0001$ ), and psychoticism (PSY; $r=-0.593 ; p<0.0001$ ). The remaining SCL-90 sub-scales showed moderate negative correlations ranging from 0.386 to 0.565 (all $p<0.0001$ ). In descending order of magnitude they were: depression (DEP), interpersonal sensibility (INT), anxiety (ANX), paranoid (PAR), hostility (HOS), somatization (SOM), phobic anxiety (PHOB), and sleep disturbance (SLEEP), with a very tight $95 \%$ confidence interval demonstrating excellent goodness of fit. 


\section{DISCUSSION}

The current study contributes to a growing literature on the benefits of protective factors on psychological functioning during high stress situations. According to our findings, dispositional mindfulness may represent a stable protective factor from the current intensity of mental distress of individuals; in fact, increasing levels of mindfulness corresponded to significantly decreased mental discomfort.

With regard to our first hypothesis which stated that certain individuals are at higher risk for psychological distress, whereas others show better adjustment to stressful situations, the results indicated that dispositional mindfulness, older age, living with loved one, and being a parent were protective factors, while female gender and lockdown duration increased the risk of psychological distress. Each increase of one unit of MAAS results in a decrease of -0.5 in GSI $(\beta=-0.504 ; p<0.0001)$, indicating that mindfulness disposition is extremely important as a psychological resource that helps the individual to manage stressful situations (Bränström et al., 2011; Rasmussen and Pidgeon, 2011; Bao et al., 2015; Dixon and Overall, 2016). Conversely, quarantining negatively affected mental health, increasing GSI of 0.05 for each week passed in lockdown. Consistent with previous studies (Di Giuseppe et al., 2019c, 2020c; Carmassi et al., 2014, 2018), younger subjects and females were at higher risk for mental health problems, while living with one's spouse resulted in them feeling slightly protected in terms of psychological wellbeing. The protective factor of mindfulness disposition and training has already been shown in previous literature, influencing positively memory function, cognitive resilience, mental health, emotional balance, and high stress functioning, also decreasing anxiety, depression, and burnout levels (Jha et al., 2010, 2017; Abenavoli et al., 2013; De Frias and Whyne, 2015; Westphal et al., 2015; Xu et al., 2017). This particular result is extremely significant as it shows that "being mindful" helps in dealing with stressful situations such as the one we are experiencing at the moment and leaves open the possibility for mental health professionals to use mindfulness-based mental training to stem the post-traumatic psychopathological beginnings that are likely to manifest in the future.

In addition to mindfulness, other protective factors emerged from our investigation. Findings showed that with increasing age, individuals showed less psychological distress. As other studies have already demonstrated, age of onset is exceedingly early for some psychopathological disorders such as anxiety, substance use, impulse control, and mood disorders (Kessler et al., 2007; Jones, 2013). Nevertheless, it has been proven that after an emergency due to natural disasters, older adults have increased resiliency to psychopathologies such as post-traumatic stress disorder, mood, and anxiety disorders (Acierno et al., 2006). Taken together, our results confirm a greater resilience in adults compared to young people with regard to high stress functioning, providing an important reflection on the direction of the efforts that mental health professionals will have to address their attention to soon. Furthermore, the social condition (cohabitants' situation during quarantine) could represent a protective factor against psychological distress. Not surprisingly, amongst the four conditions proposed in our survey, "living with a partner" predicted lower distress during the COVID19 quarantine. According to previous studies, social relations are indeed a protective factor for mental health, increasing resilience (Fuller-Iglesias et al., 2008) but our findings showed that to be significant, it should come from loved ones. In fact, separation from loved ones seems to be the crucial psychological distress factor during quarantine, despite the support of new devices that are keeping us connected (Maunder et al., 2003; Manuell and Cukor, 2011; Brooks et al., 2020). Furthermore, 'being a parent' seems to be a protective condition against mental illness, as already reported in other studies (Helbig et al., 2006; Nelson et al., 2014).

Conversely, gender and lockdown duration were good predictors of higher distress among Italians. Female gender seems to be solidly related with higher psychological distress than male gender. As well known, men and women experience different kinds of mental health problems; females tend to exceed males in internalizing disorders with higher prevalence of depression and anxiety (Rosenfield, 1999; Rosenfield and Mouzon, 2013). This gap narrows with the temporal and spatial variation in gender role traditionality (Seedat et al., 2009). There is no doubt that particular attention should be paid to women in this crucial period, who, in addition to being at greater risk of developing a mood disorder or suffering from psychological distress, are unfortunately the main victims of domestic violence (Bradbury-Jones and Isham, 2020; Taub, 2020). Furthermore, the economic downturn caused by this emergency is more likely to impact sectors with high female employment shares, together with the increasing needs in childcare (Alon et al., 2020). Finally, our findings suggested that lockdown duration has a negative impact on mental health; a previous study displayed in the first phase of the Italian quarantine had already reported that individuals in quarantine experienced negative psychosocial changes such as sleep disturbances, post-traumatic symptoms, depression, and anxiety which all have a massive impact on wellbeing (Brooks et al., 2020; Cellini et al., 2020; Wang et al., 2020; Di Giuseppe et al., 2020d).

Our second hypothesis of a strong negative relationship between mindfulness and psychiatric symptoms of distress was fully confirmed. Mindfulness was found to be negatively correlated with all the analyzed subscales. In particular, individuals with lower mindfulness disposition are more likely to present thoughts, impulses, and actions that are experienced as irresistible but are of an unwanted nature, and cognitive attenuation (Obsessive-compulsive subscale). In addition, lower mindfulness predicted the experience of withdrawal, isolation, and a schizoid lifestyle and also on first-rank schizophrenia symptoms such as hallucinations and thought-broadcasting (Psychoticism subscale; Matti, 2003). Moreover, significant moderate correlations were found for all psychiatric symptoms assessed with the SCL-90, with greater magnitude on interpersonal sensitivity, depression, and anxiety. Results demonstrated that a higher disposition toward mindfulness may represent a protective factor against anxiety, dysphoric mood, lack of motivation, loss of vital energy, feelings of hopelessness, and cognitive and other somatic correlates of 
depression, as already shown in previous studies (Teasdale et al., 2000; Evans et al., 2008; Walsh et al., 2009; Deng et al., 2014; Segal and Teasdale, 2018).

The present study has several strengths and innovative features, as well as a number of limitations. First, the crosssectional research design does not allow us to determine causal relationships between studied variables (Pearl, 2010; Orrù et al., 2020,a,b). Moreover, we used a non-randomized sampling method, the so-called snowball sampling, which could be possibly biased by uncontrolled variables. Furthermore, all measures are self-reported and thus they might be biased by the responders' self-observation attitude. Finally, psychological information was collected online and without any independent evaluation of the health status of the respondents.

Despite all the above, this study indicates that mindfulness and socio-demographic characteristics play a key role in moderating the experience of COVID-19-related distress. Mindfulness dispositions and practice, as with other psychological resources (Lingiardi et al., 2010; Fonagy and Bateman, 2016; Prout et al., 2019; Di Giuseppe et al., 2020e), enhances adaptation and leads to a better adjustment to stress (Maffei et al., 1995; Di Giuseppe et al., 2019a; Marazziti et al., 2020). In order to stem the psychopathological consequences lying ahead in the future due to the traumatic nature of the recent pandemic and quarantine, we therefore suggest paying accurate attention to mindfulness disposition and training, with the purpose of

\section{REFERENCES}

Aafjes-van Doorn, K., Békés, V., and Prout, T. A. (2020). Grappling with our therapeutic relationship and professional self-doubt during COVID-19: will we use video therapy again?. Counsel. Psychol. Q. doi: 10.1080/09515070.2020. 1773404

Abenavoli, R. M., Jennings, P. A., Greenberg, M. T., Harris, A. R., and Katz, D. A. (2013). The protective effects of mindfulness against burnout among educators. Psychol. Educ. Rev. 37, 57-69.

Acierno, R., Ruggiero, K. J., Kilpatrick, D. G., Resnick, H. S., and Galea, S. (2006). Risk and protective factors for psychopathology among older versus younger adults after the 2004 Florida hurricanes. Am. J. Geriatr. Psychiatry 14, 1051-1059. doi: 10.1097/01.JGP.0000221327.97904.b0

Alon, T. M., Doepke, M., Olmstead-Rumsey, J., and Tertilt, M. (2020). The Impact of COVID-19 on Gender Equality. Economic Fluctuations and Growth No. w26947. Cambridge, MA: National Bureau of Economic Research.

Baer, R. A. (2003). Mindfulness training as a clinical intervention: a conceptual and empirical review. Clin. Psychol. Sci. Pract. 10, 125-143. doi: 10.1093/clipsy. bpg015

Baer, R. A., Smith, G. T., and Allen, K. B. (2004). Assessment of mindfulness by selfreport: the kentucky inventory of mindfulness skills. Assessment 11, 191-206. doi: $10.1177 / 1073191104268029$

Baer, R. A., Smith, G. T., Hopkins, J., Krietemeyer, J., and Toney, L. (2006). Using self-report assessment methods to explore facets of mindfulness. Assessment 13, 27-45. doi: 10.1177/1073191105283504

Bao, X., Xue, S., and Kong, F. (2015). Dispositional mindfulness and perceived stress: the role of emotional intelligence. Pers. Individ. Diff. 78, 48-52. doi: 10.1016/j.paid.2015.01.007

Black, D. S., Sussman, S., Johnson, C. A., and Milam, J. (2012). Psychometric assessment of the mindful attention awareness scale (MAAS) among Chinese adolescents. Assessment 19, 42-52. doi: 10.1177/1073191111415365

Bonicatto, S., Dew, M. A., Soria, J. J., and Seghezzo, M. E. (1997). Validity and. (reliability)of Symptom Checklist '90 (SCL90) in an Argentine population sample. Soc. Psychiatry Psychiatr. Epidemiol. 32, 332-338. doi: 10.1007/ BF00805438 enhancing resilience to high-stress events and preventing the onset of chronic mental disorders.

\section{DATA AVAILABILITY STATEMENT}

The raw data supporting the conclusions of this article will be made available by the authors, without undue reservation, to any qualified researcher.

\section{ETHICS STATEMENT}

The studies involving human participants were reviewed and approved by the Ethics Committee of the University of Pisa. The patients/participants provided their written informed consent to participate in this study.

\section{AUTHOR CONTRIBUTIONS}

$\mathrm{CC}$ and MD conceived the assessment. MM contributed to the data analysis. RC contributed to the data interpretation. CC, MD, MM, RC, AG, and GO drafted the manuscript. All authors critically revised the manuscript and approved the final version to be published.

Bradbury-Jones, C., and Isham, L. (2020). The pandemic paradox: the consequences of COVID-19 on domestic violence. J. Clin. Nurs. [Epub ahead of print]. doi: 10.1111/jocn.15296

Bränström, R., Duncan, L. G., and Moskowitz, J. T. (2011). The association between dispositional mindfulness, psychological well-being, and perceived health in a Swedish population-based sample. Br. J. Health Psychol. 16, 300-316. doi: 10.1348/135910710X501683

Brooks, S. K., Webster, R. K., Smith, L. E., Woodland, L., Wessely, S., Greenberg, N., et al. (2020). The psychological impact of quarantine and how to reduce it: rapid review of the evidence. Lancet 395, 912-920. doi: 10.1016/S0140-6736(20) 30460-8

Brown, K. W., and Ryan, R. M. (2003). The benefits of being present: mindfulness and its role in psychological well-being. J. Pers. Soc. Psychol. 84:822. doi: 10. 1037/0022-3514.84.4.822

Carmassi, C., Gesi, C., Corsi, M., Cremone, I. M., Bertelloni, C. A., Massimetti, E., et al. (2018). Exploring PTSD in emergency operators of a major University Hospital in Italy: a preliminary report on the role of gender, age, and education. Ann. Gen. Psychiatry 17:17. doi: 10.1186/s12991-0180184-4

Carmassi, C., Stratta, P., Massimetti, G., Bertelloni, C. A., Conversano, C., Cremone, I. M., et al. (2014). New DSM-5 maladaptive symptoms in PTSD: gender differences and correlations with mood spectrum symptoms in a sample of high school students following survival of an earthquake. Ann. Gen. Psychiatry 13:28. doi: 10.1186/s12991-014-0028-9

Cassano, G., Conti, L., and Levine, J. (1999). “SCL-90,” in Repertorio delle scale di valutazione in psichiatria, ed. L. Conti (Firenze: SEE), 325-332.

Catalano, A., Martino, G., Bellone, F., Papalia, M., Lasco, C., Basile, G., et al. (2019). Neuropsychological assessment in elderly men with benign prostatic hyperplasia treated with dutasteride". Clin. Drug Investig. 39, 97-102. doi: 10. 10007/s40261-018-0720-7

Cellini, N., Canale, N., Mioni, G., and Costa, S. (2020). Changes in sleep pattern, sense of time, and digital media use during COVID-19 lockdown in Italy. J. Sleep Res. 29:e13074. doi: 10.31234/osf.io/284mr

Chang, V. Y., Palesh, O., Caldwell, R., Glasgow, N., Abramson, M., Luskin, F., et al. (2004). The effects of a mindfulness-based stress reduction program on stress, 
mindfulness self-efficacy, and positive states of mind. Stress Health 20, 141-147. doi: $10.1002 /$ smi.1011

Chu, C. S., Stubbs, B., Chen, T. Y., Tang, C. H., Li, D. J., Yang, W. C., et al. (2018). The effectiveness of adjunct mindfulness-based intervention in treatment of bipolar disorder: a systematic review, and meta-analysis. J. Affect Disord. 225, 234-245. doi: 10.1016/j.jad.2017.08.025

Conversano, C. (2019). Common psychological factors in chronic diseases. Front. Psychol. 10:2727. doi: 10.3389/fpsyg.2019.02727

Conversano, C., Ciacchini, R., Orrù, G., Di Giuseppe, M., Gemignani, A., and Poli, A. (2020a). Mindfulness, self-compassion, and empathy among health care professionals: what's new? A systematic review. Front. Psychol. 20:1683. doi: $10.3389 /$ fpsyg. 2020.01683

Conversano, C., Marchi, L., and Miniati, M. (2020b). Psychological distress among healthcare professionals involved in the COVID-19 emergency: vulnerability and resilience factors. Clin. Neuropsychiatry 17, 94-96. doi: 10. $36131 / \mathrm{CN} 20200212$

Costa, P. T. Jr., and McCrae, R. R. (2008). “The Revised NEO Personality Inventory (NEO-PI-R)," in The SAGE Handbook of Personality Theory and Assessment, Vol. 2. Personality Measurement and Testing, eds G. J. Boyle, G. Matthews, and D. H. Saklofske (Thousand Oaks, CA: Sage Publications, Inc), 179-198. doi: $10.4135 / 9781849200479 . n 9$

Davidson, R. J., Kabat-Zinn, J., Schumacher, J., Rosenkranz, M., Muller, D., Santorelli, S. F., et al. (2003). Alterations in brain and immune function produced by mindfulness meditation. Psychos. Med. 65, 564-570. doi: 10.1097/ 01.PSY.0000077505.67574.E3

De Frias, C. M., and Whyne, E. (2015). Stress on health-related quality of life in older adults: the protective nature of mindfulness. Aging Ment. Health 19, 201-206. doi: 10.1080/13607863.2014.924090

Dell'Osso, L., Casu, G., Carlini, M., Conversano, C., Gremigni, P., and Carmassi, C. (2012). Sexual obsessions and suicidal behaviors in patients with mood disorders, panic disorder and schizophrenia. Ann. Gen. Psychiatry 11:27. doi: 10.1186/1744-859X-11-27

Deng, Y. Q., Li, S., and Tang, Y. Y. (2014). The relationship between wandering mind, depression and mindfulness. Mindfulness 5, 124-128. doi: 10.1007/ s12671-012-0157-7

Derogatis, L. R., and Cleary, P. A. (1977). Confirmation of the dimensional structure of the SCL-90: a study in construct validation. J. Clin. Psychol. 33, 981-989. doi: 10.1002/1097-4679(197710)33:4<981::aid-jclp2270330412>3.0. co;2-0

Derogatis, L. R., Lipman, R. S., and Covi, L. (1973). SCL-90: an outpatient psychiatric rating scale: preliminary report. Psychopharmacol. Bull. 9, 13-27.

Derogatis, L. R., Rickels, K., and Rock, A. F. (1976). The SCL-90 and the MMPI: a step in the validation of a new self-report scale. Br. J. Psychiatry 128, 280-289. doi: $10.1192 /$ bjp.128.3.280

Di Giuseppe, M., Ciacchini, R., Micheloni, T., Bertolucci, I., Marchi, L., and Conversano, C. (2018). Defense mechanisms in cancer patients: a systematic review. J. Psychosom. Res. 115, 76-86. doi: 10.1016/j.jpsychores.2018.10.016

Di Giuseppe, M., Ciacchini, R., Piarulli, A., Nepa, G., and Conversano, C. (2019a). Mindfulness disposition and defense style as a positive responses to psychological distress in oncology professionals. Eur. J. Oncol. Nurs. 40, 104-110. doi: 10.1016/j.ejon.2019.04.003

Di Giuseppe, M., Di Silvestre, A., Lo Sterzo, R., Hitchcott, P., Gemignani, A., and Conversano, C. (2019b). Qualitative and quantitative analysis of the defense profile in Breast Cancer women: a pilot study. Health Psychol. Open 6:2055102919854667. doi: 10.1177/2055102919854667

Di Giuseppe, M., Gemignani, A., and Conversano, C. (2020a). Psychological resources against the traumatic experience of COVID-19. Clin. Neuropsychiatry 17, 85-87. doi: 10.36131/CN20200207

Di Giuseppe, M., Gennaro, A., Lingiardi, V., and Perry, J. C. (2019c). The role of defense mechanisms in emerging personality disorders in clinical adolescents. Psychiatry 82, 128-142. doi: 10.1080/00332747.2019.1579595

Di Giuseppe, M., Miniati, M., Miccoli, M., Ciacchini, R., Orrù, G., Lo Sterzo, R., et al. (2020b). Defensive responses to stressful life events associated with cancer diagnosis. Mediterranean J. Clin. Psychol. 8. doi: 10.6092/2282-1619/mjcp2384

Di Giuseppe, M., Perry, J. C., Conversano, C., Gelo, O. C. G., and Gennaro, A. (2020c). Defense mechanisms, gender and adaptiveness in emerging personality disorders in adolescent outpatients. J. Nerv. Ment. Dis. 8. doi: 10.1080/ 00332747.2019.1579595
Di Giuseppe, M., Perry, J. C., Lucchesi, M., Michelini, M., Vitiello, S., Piantanida, A., et al. (2020d). Preliminary validity and reliability of the novel selfreport based on the Defense Mechanisms Rating Scales (DMRS-SR-30). Front. Psychiatry 11:870. doi: 10.3389/fpsyt.2020.00870

Di Giuseppe, M., Prout, T. A., Fabiani, M., and Kui, T. (2020e). Defensive profile of parents of children with externalizing problems receiving regulation-focused psychotherapy for children (RFP-C): a pilot study. Mediterranean J. Clin. Psychol. 8. doi: 10.6092/2282-1619/mjcp- 2515

Dixon, H. C., and Overall, N. C. (2016). Dispositional mindfulness attenuates the link between daily stress and depressed mood. J. Soc. Clin. Psychol. 35, 255-268. doi: 10.1521/jscp.2016.35.3.255

Evans, S., Ferrando, S., Findler, M., Stowell, C., Smart, C., and Haglin, D. (2008). Mindfulness-based cognitive therapy for generalized anxiety disorder. J. Anxiety Disord. 22, 716-721. doi: 10.1016/j.janxdis.2007.07.005

Fisher, S., Guralnik, T., Fonagy, P., and Zilcha-Mano, S. (2020). Let's face it: video conferencing psychotherapy requires the extensive use of ostensive cues. Counsel. Psychol. Q. doi: 10.1080/09515070.2020.1777535

Fonagy, P., and Bateman, A. W. (2016). Adversity, attachment, and mentalizing. Compr. Psychiatry 64, 59-66. doi: 10.1016/j.comppsych.2015.11.006

Fuller-Iglesias, H., Sellars, B., and Antonucci, T. C. (2008). Resilience in old age: social relations as a protective factor. Res. Hum. Dev. 5, 181-193. doi: 10.1080/ 15427600802274043

Geng, L., Wang, J., Cheng, L., Zhang, B., and Shen, H. (2019). Mindful learning improves positive feelings of cancer patients' family caregivers. Int. J. Environ. Res. Public Health 16:248. doi: 10.3390/ijerph16020248

Helbig, S., Lampert, T., Klose, M., and Jacobi, F. (2006). Is parenthood associated with mental health? Soc. Psychiatry Psychiatr. Epidemiol. 41, 889-896. doi: 10. 1007/s00127-006-0113-8

Holmes, E. A., O'Connor, R. C., Perry, V. H., Tracey, I., Wessely, S., Arseneault, L. et al. (2020). Multidisciplinary research priorities for the COVID-19 pandemic: a call for action for mental health science. Lancet Psychiatry 7, 547-560. doi: 10.1016/S2215-0366(20)30168-1

Idusohan-Moizer, H., Sawicka, A., Dendle, J., and Albany, M. (2015). Mindfulnessbased cognitive therapy for adults with intellectual disabilities: an evaluation of the effectiveness of mindfulness in reducing symptoms of depression, and anxiety. J. Intellect. Disabil. Res. 59, 93-104. doi: 10.1111/jir.12082

Jha, A. P., Morrison, A. B., Parker, S. C., and Stanley, E. A. (2017). Practice is protective: mindfulness training promotes cognitive resilience in high-stress cohorts. Mindfulness 8, 46-58. doi: 10.1007/s12671-015-0465-9

Jha, A. P., Stanley, E. A., Kiyonaga, A., Wong, L., and Gelfand, L. (2010). Examining the protective effects of mindfulness training on working memory capacity and affective experience. Emotion 10:54. doi: 10.1037/a0018438

Jones, P. B. (2013). Adult mental health disorders and their age at onset. Br. J. Psychiatry 202, s5-s10. doi: 10.1192/bjp.bp.112.119164

Kabat-Zinn, J. (2003). Mindfulness-based interventions in context: past, present, and future. Clin. Psychol. Sci. Pract. 10, 144-156. doi: 10.1093/clipsy.bpg016

Kabat-Zinn, J. (2015). Mindfulness. Mindfulness 6, 1481-1483. doi: 10.1007/ s12671-015-0456- $\mathrm{x}$

Kessler, R. C., Angermeyer, M., Anthony, J. C., De Graaf, R., Demyttenaere, K., Gasquet, I., et al. (2007). Lifetime prevalence and age-of-onset distributions of mental disorders in the world health organization's world mental health survey initiative. World Psychiatry 6, 168-176.

Kwon, J., Grady, C., Feliciano, J. T., and Fodeh, S. J. (2020). Defining facets of social distancing during the COVID-19 pandemic: twitter analysis. MedRxiv [Preprint]. doi: 10.1101/2020.04.26.20080937

Lam, A. H. Y., Leung, S. F., Lin, J. J., and Chien, W. T. (2020). The effectiveness of a mindfulness-based psychoeducation programme for emotional regulation in individuals with schizophrenia spectrum disorders: a pilot randomised controlled trial. Neuropsychiatr. Dis. Treat. 16, 729-747. doi: 10.2147/NDT. S231877

Lara, M. C., Espinosa, S. I., Cárdenas, M. L., et al. (2005). Reliability, and validity of the SCL-90 for the evaluation of psychopathology in women. Salud Mental 28, $42-50$.

Lenzo, V., Sardella, A., Martino, G., and Quattropani, M. C. (2020). A systematic review of metacognitive beliefs in chronic medical conditions. Front. Psychol. 10:2875. doi: 10.3389/fpsyg.2019.02875

Li, S., Wang, Y., Xue, J., Zhao, N., and Zhu, T. (2020). The impact of COVID-19 epidemic declaration on psychological consequences: a study on active Weibo users. Int. J. Environ. Res. Public Health 17:2032. doi: 10.3390/ijerph17062032 
Lingiardi, V., Gazzillo, F., Colli, A., De Bei, F., Tanzilli, A., Di Giuseppe, M., et al. (2010). Diagnosis and assessment of personality, therapeutic alliance and clinical exchange in psychotherapy research. Res. Psychother. 2, 97-124.

Maffei, C., Fossati, A., Lingiardi, V., Madeddu, F., Borellini, C., and Petrachi, M. (1995). Personality maladjustment, defenses, and psychopathological symptoms in nonclinical subjects. J. Personal. Disord. 9, 330-345. doi: 10.1521/ pedi.1995.9.4.330

Manuell, M. E., and Cukor, J. (2011). Mother Nature versus human nature: public compliance with evacuation and quarantine. Disasters 35, 417-442. doi: 10. 1111/j.1467-7717.2010.01219.x

Marazziti, D., Golia, F., Picchetti, M., Pioli, E., Mannari, P., Lenzi, F., et al. (2008). Decreased density of the platelet serotonin transporter in pathological gamblers. Neuropsychobiology 57, 38-43. doi: 10.1159/000129665

Marazziti, D., Pozza, A., Di Giuseppe, M., and Conversano, C. (2020). The psychosocial impact of COVID-19 pandemic in Italy: a lesson for mental health prevention in the first severely hit European country. Psychol. Trauma 12, 531-533. doi: $10.1037 /$ tra0000687

Marazziti, D., Tomaiuolo, F., Dell'Osso, L., Demi, V., Campana, S., Piccaluga, E., et al. (2015). Neuropsychological testing in interventional cardiology staff after long-term exposure to ionizing radiation. J. Int. Neuropsychol. Soc. 21, 670-676. doi: $10.1017 /$ S135561771500082X

Marchi, L., Marzetti, F., Orrù, G., Lemmetti, S., Miccoli, M., Ciacchini, R., et al. (2019). Alexitimia and psychological distress in patients with fibromyalgia and rheumatic disease. Front. Psychol. 10:1735.

Martino, G., Bellone, F., Langher, V., Caputo, A., Catalano, A., Quattropani, M. C., et al. (2019a). Alexithymia and psychological distress affect perceived quality of life in patients with type 2 diabetes mellitus. Mediterranean J. Clin. Psychol. 7. doi: 10.6092/2282-1619/2019.7.2328

Martino, G., Catalano, A., Bellone, F., Russo, G. T., Vicario, C. M., Lasco, A., et al. (2019b). As time goes by: anxiety negatively affects the perceived quality of life in patients with type 2 diabetes of long duration. Front. Psychol. 10:1779. doi: $10.3389 /$ fpsyg.2019.01779

Martino, G., Caputo, A., Bellone, F., Quattropani, M. C., and Vicario, C. (2020a). Going beyond the visible in type 2 diabetes mellitus: defense mechanisms and their associations with depression and health-related quality of life. Front. Psychol. 11:267. doi: 10.3389/fpsyg.2020.00267

Martino, G., Catalano, A., Agostino, R. M., Bellone, F., Morabito, N., Lasco, C. G., et al. (2020b). Quality of life and psychological functioning in postmenopausal women undergoing aromatase inhibitor treatment for early breast cancer. PLoS One 15:e0230681. doi: 10.1371/journal.pone.0230681

Martino, G., Langher, V., Cazzato, V., and Vicario, C. M. (2019c). Editorial: psychological factors as determinants of medical conditions. Front. Psychol. 10:2502. doi: 10.3389/fpsyg.2019.02502

Matti, H. (2003). Assessment of Psychiatric Symptoms using the SCL-90. Helsingin Yliopisto 15, 203-211.

Maunder, R., Hunter, J., Vincent, L., Bennett, J., Peladeau, N., Leszcz, M., et al. (2003). The immediate psychological and occupational impact of the 2003 SARS outbreak in a teaching hospital. CMAJ 168, 1245-1251.

Merlo, E. M. (2019). Opinion article: the role of psychological features in chronic diseases, advancements and perspectives. Mediterranean J. Clin. Psychol. 7. doi: 10.6092/2282-1619/2019.7.2341

Mula, M., Pini, S., Monteleone, P., Iazzetta, P., Preve, M., Tortorella, A., et al. (2008). Different temperament and character dimensions correlate with panic disorder comorbidity in bipolar disorder and unipolar depression. J. Anxiety Disord. 22, 1421-1426. doi: 10.1016/j.janxdis.2008.02.004

Muratori, P., and Ciacchini, R. (2020). Children and the COVID-19 transition: psychological reflections and suggestions on adapting to the emergency. ClinNeuropsychiatry 17, 131-134. doi: 10.36131/CN20200219

Nelson, S. K., Kushlev, K., and Lyubomirsky, S. (2014). The pains and pleasures of parenting: when, why, and how is parenthood associated with more or less well-being? Psychol. Bull. 140, 846-895. doi: 10.1037/a0035444

Orrù, G., Ciacchini, A., Gemignani, A., and Conversano, C. (2020). Psychological intervention measures during the COVID-19 pandemic. Clin. Neuropsychiatry 17, 76-79. doi: 10.36131/CN20200208

Orrù, G., Gemignani, A., Ciacchini, R., Bazzichi, L., and Conversano, C. (2020a). Machine learning increases diagnosticity in psychometric evaluation of alexithymia in fibromyalgia. Front. Med. 6:319. doi: 10.3389/fmed.2019.00319
Orrù, G., Monaro, M., Conversano, C., Gemignani, A., and Sartori, G. (2020b). Machine learning in psychometrics and psychological research. Front. Psychol. 10:2970. doi: 10.3389/fpsyg.2019.02970

Pearl, J. (2010). An introduction to causal inference. Int. J. Biostat. 6:7. doi: 10.2202/ 1557-4679.1203

Piccinni, A., Origlia, N., Veltri, A., Vizzaccaro, C., Marazziti, D., Catena-Dell'Osso, M., et al. (2012). Plasma $\beta$-amyloid peptides levels: a pilot study in bipolar depressed patients. J. Affect. Disord. 138, 160-164. doi: 10.1016/j.jad.2011. 12.042

Poli, A., Gemignani, A., and Conversano, C. (2020). The psychological impact of SARS-CoV-2 quarantine: observations through the lens of the polyvagal theory. Clin. Neuropsychiatry 17, 112-114. doi: 10.36131/CN20200216

Prout, T. A., Malone, A., Rice, T., and Hoffman, L. (2019). Resilience, defenses, and implicit emotion regulation in psychodynamic child psychotherapy. J. Contemp. Psychother. 49, 235-244. doi: 10.1007/s10879-019-09423-w

Rasmussen, M. K., and Pidgeon, A. M. (2011). The direct and indirect benefits of dispositional mindfulness on self-esteem and social anxiety. Anxiety Stress Coping 24, 227-233. doi: 10.1080/10615806.2010.515681

Rosenfield, S. (1999). "Gender and mental health: do women have more psychopathology, men more, or both the same (and why)?", in A handbook for the Study of Mental Health: Social Contexts, Theories, and Systems, eds A. V. Horwitz and T. L. Scheid (Cambridge, MA: Cambridge University Press), 348-360.

Rosenfield, S., and Mouzon, D. (2013). "Gender and mental health," in Handbooks of Sociology and Social Research. Handbook of the Sociology of Mental Health, eds C. S. Aneshensel, J. C. Phelan, and A. Bierman (Cham: Springer), 277-296.

Ryan, R. M., and Deci, E. L. (2000). Self-determination theory and the facilitation of intrinsic motivation, social development, and well-being. Am. Psychol. 55, 68-78. doi: 10.1037/0003-066x.55.1.68

Salovey, P., Mayer, J. D., Goldman, S. L., Turvey, C., and Palfai, T. F. (1995). "Emotional attention, clarity, and repair: exploring emotional intelligence using the trait meta-mood scale," in Emotion, Disclosure, and Health, ed. J. W. Pennebaker (Washington, DC: American Psychological Association), 125-154. doi: 10.1037/10182-006

Sartori, G., Zangrossi, A., Orrù, G., and Monaro, M. (2017). Detection of Malingering in Psychic Damage Ascertainment in P5 Medicine and Justice. Cham: Springer, 330-341.

Seedat, S., Scott, K. M., Angermeyer, M. C., Berglund, P., Bromet, E. J., Brugha, T. S., et al. (2009). Cross-national associations between gender and mental disorders in the World Health Organization World Mental Health Surveys. Arch. Gen. Psychiatry 66, 785-795. doi: 10.1001/archgenpsychiatry.20 09.36

Segal, Z. V., and Teasdale, J. (2018). Mindfulness-Based Cognitive Therapy for Depression. New York, NY: Guilford Publications.

Shear, J., and Jevning, R. (1999). Pure consciousness: scientific exploration of meditation techniques. J. Conscious. Stud. 6, 189-210.

Soysa, C. K., and Wilcomb, C. J. (2015). Mindfulness, self-compassion, selfefficacy, and gender as predictors of depression, anxiety, stress, and well-being. Mindfulness 6, 217-226. doi: 10.1007/s12671-013-0247-1

Strauss, C., Cavanagh, K., Oliver, A., and Pettman, D. (2014). Mindfulness-based interventions for people diagnosed with a current episode of an anxiety or depressive disorder: a meta-analysis of randomised controlled trials. PLoS One 9:e96110. doi: 10.1371/journal.pone.0096110

Tang, Y., Hölzel, B., and Posner, M. (2015). The neuroscience of mindfulness meditation. Nat. Rev. Neurosci. 16, 213-225. doi: 10.1038/nrn3916

Taub, A. (2020). A new Covid-19 Crisis: Domestic Abuse Rises Worldwide. New York, NY: The New York Times.

Teasdale, J. D., Segal, Z. V., Williams, J. M. G., Ridgeway, V. A., Soulsby, J. M., and Lau, M. A. (2000). Prevention of relapse/recurrence in major depression by mindfulness-based cognitive therapy. J. Consult. Clin. Psychol. 68, 615-623. doi: 10.1037/0022-006X.68.4.615

Veltri, A., Scarpellini, P., Piccinni, A., Conversano, C., Giacomelli, C., Bombardieri, S., et al. (2012). Methodological approach to depressive symptoms in fibromyalgia patients. Clin. Exp. Rheumatol 30(Suppl. 74), S136-S142.

Veneziani, C. A., and Voci, A. (2015). The italian adaptation of the mindful awareness attention scale, and its relation with individual differences, and 
quality of life indexes. Mindfulness 6, 373-381. doi: 10.1007/s12671-0130270-2

Walsh, J. J., Balint, M. G., Sj, D. R. S., Fredericksen, L. K., and Madsen, S. (2009). Predicting individual differences in mindfulness: the role of trait anxiety, attachment anxiety and attentional control. Pers. Individ. Diff. 46, 94-99. doi: 10.1016/j.paid.2008.09.008

Wang, C., Pan, R., Wan, X., Tan, Y., Xu, L., McIntyre, R. S., et al. (2020). A longitudinal study on the mental health of general population during the COVID-19 epidemic in China. Brain Behav. Immun. 87, 40-48. doi: 10.1016/ j.bbi.2020.04.028

Westphal, M., Bingisser, M. B., Feng, T., Wall, M., Blakley, E., Bingisser, R., et al. (2015). Protective benefits of mindfulness in emergency room personnel. J. Affect. Disord. 175, 79-85. doi: 10.1016/j.jad.2014.12.038

Xu, M., Purdon, C., Seli, P., and Smilek, D. (2017). Mindfulness and mind wandering: the protective effects of brief meditation in anxious individuals. Conscious. Cogn. 51, 157-165. doi: 10.1016/j.concog.2017.03.009
Zhang, M. F., Wen, Y. S., Liu, W. Y., Peng, L. F., Wu, X. D., and Liu, Q. W. (2015). Effectiveness of mindfulness-based therapy for reducing anxiety and depression in patients with cancer: a meta-analysis. Medicine 94:e0897. doi: 10.1097/MD.0000000000000897

Conflict of Interest: The authors declare that the research was conducted in the absence of any commercial or financial relationships that could be construed as a potential conflict of interest.

Copyright (C) 2020 Conversano, Di Giuseppe, Miccoli, Ciacchini, Gemignani and Orrù. This is an open-access article distributed under the terms of the Creative Commons Attribution License (CC BY). The use, distribution or reproduction in other forums is permitted, provided the original author(s) and the copyright owner(s) are credited and that the original publication in this journal is cited, in accordance with accepted academic practice. No use, distribution or reproduction is permitted which does not comply with these terms. 